\title{
STUDENTS' ATTRIBUTIONS ON THEIR ENGLISH SPEAKING ENHANCEMENT
}

\author{
Yustinus Calvin Gai Mali \\ Satya Wacana Christian University, Salatiga \\ email: calvin.yustinus@yahoo.com
}

Article received: 10 August 2014

Final proof received: 6 December 2014

\begin{abstract}
Attribution refers to explanations and reasons that people provide for progress, achievement, and even failure towards something they have experienced, particularly in their language learning. This study aimed to investigate the attributions that students had for their English-speaking enhancement. The participants of the study were eighteen students at Sekolah Tinggi Pariwisata Ambarukmo Yogyakarta (STIPRAM). Open-ended questionnaire and interview were used as the instruments to collect the data. On the questionnaire, the participants were specifically asked to provide written responses to three statements, while in the interview process, the researcher involved three participants to provide further clarification toward their written responses on the questionnaire. The data analysis revealed that a clear purpose of doing particular English speaking activities, strategy, and the positive motivation/encouragement from friends as well as from the teacher became the major students' attributions on their English-speaking enhancement. Besides, this study would seem to indicate that a teacher took an essential role in the enhancement of the students' English speaking skill. Eventually, this study proposed some pedagogical implications for the development of teaching and learning in English speaking classes specifically in Indonesian context.
\end{abstract}

Keywords: attributions, English speaking skill, enhancement

The term attribution is closely related to explanations and reasons that people provide for progress, achievement, and even failure towards something they have experienced, particularly in their language learning. Asonibare (1986) defines attribution as a cognitive process by which a person perceives a consequence that is caused by himself or other people, towards what has happened to him. With similar views, attribution theory reflects a situation where people look for causes for successes and failures they have experienced (Mori, Gobel, Thepsiri, \& Pojanapunya, 2010) and where students try to interpret the outcomes of their achievement specifically how they explain their success and failure, by attributing causes to them (Eccles \& Wigfield, 2002; Weiner, 1985; 1994, as cited in Yilmaz,
2012). The term could also be regarded as an explanation that learners provide for progress of their second language learning (Ellis, 2008) and as reasons that learners attribute to their success or failure when they are in the process of learning a target language (Gonzales, 2011).

In an educational context, the fact that the attribution on students' learning process has been regarded as a key factor that influences their learning motivation and academic achievement is undeniable. The attribution process becomes an essential determinant of learning and performance in a classroom (Weiner, 1972) and it could influence students' motivation (Ellis, 2008). Similarly, Lei (2009) points out that attribution made toward the success or failure in studying will result in changes in 
expectations and emotions, which possibly affect motivation that individuals have for learning and subsequently for their academic achievement. Besides, students' attribution on their success and failure can significantly have an impact on their future performance of academic tasks (Banks \& Woolfson, 2008).

Highlighting the importance of exploring students' attributions, a number of related studies were carried out internationally. Tse (2000) conducted a qualitative study involving fifty-one university students who learnt a foreign language while they were studying in the United States. The study revealed that their teachers and professors' willingness to support their learning as well as language input received from their family and community interactions become the most frequent attributions stated by the students for the success in their learning. On the other hand, most of the students blamed themselves for having low level of success in the study of their foreign language. In that case, they admitted that they did not have enough practice and not spend their time sufficiently to study the language.

Another study by Williams, Burden, Poulet, and Maun (2004) sought to investigate attributions of two hundred and eighty five students studying French, German, and Spanish in five secondary schools in the United Kingdom. Their study revealed twenty-one attribution categories, in which effort, strategy, ability, and teacher become frequently cited attributions for doing well in their learning. Contrary to the results of attributions for doing well, the study stated sixteen attribution categories in which lack of effort, ability, and interest become the primary reasons for not doing well in their learning.

Gobel and Mori (2007) have carried out a more recent study. Administering an open questionnaire, they attempted to explore reasons for success and failures among the first year Japanese university students in their speaking and reading classes. The findings asserted that internal factors became the attributions for the students' failure in their classes and regarded external factors as the attributions for their success.

Lei and Qin (2009) as cited in Pishghadam and Zabihi, (2011) undertook another related study. They attempted to explore the relationship between Chinese English as a foreign language (EFL) learners' attributions and their English learning achievement. Significantly, they revealed that teacher and effort became attribution factors that predicted their success in learning EFL.

With regard to English as a Second Language (ESL) students in six public universities in Malaysia, Thang, Gobel, Mohd.Nor, \& Suppiah, (2011) investigated the relationship between students' performance attributions and different university settings in their ESL learning. The results indicated that most of the students in the universities regarded interest in getting a good grade and teacher influence as the primary attributions for their success in their ESL learning. On the other hand, the attributions for the failure were closely related to their preparation, ability, and effort.

In Turkey, Yilmaz (2012) conducted a study that involved ninety-one undergraduate university students studying EFL and focused its analysis on the attributions that students made on their reading comprehension. The results reported ten reasons for their success in their reading comprehension. Some of the reasons were good strategies, positive mood, interest in reading, good teachers' feedback, and positive environment. Then, from thirteen cited attributions for not doing well in their reading comprehension, lack of interest in reading, lack of time, as well as negative 
mood and environment become the frequently cited attributions by the students.

The previous related studies (Tse, 2000; Williams, et al., 2004; Gobel \& Mori, 2007; Lei \& Qin, 2009 as cited in Pishghadam \& Zabihi, 2011; Thang, et al., 2011; Yilmaz, 2012) that the researcher has reviewed seem to focus on exploring students' attributions generally towards their ESL and EFL learning. To the best of the researcher's knowledge, there have been few numbers of studies sought to explore the students' attributions in learning a particular skill, in this case, speaking, regarded as an essential part of the curriculum in language teaching (Luoma, 2004) and said to seem naturally essential, since many foreign language learners are primarily interested in learning to speak (Ur, 1996). Besides, there have not been plethora studies attempted to explore the issues specifically in a non-English Department setting in Indonesia, where English is considered as a foreign language. Therefore, the primary purpose of this study was generally to explore students' attributions in a speaking class since the students might conceivably have their personal attributions for their learning experience in the class. In addition, given the importance of exploring the attributions, this study specifically aimed to answer the following research question: What are students' attributions for the enhancement of their English speaking ability in English Speaking Community (ESC) class?

\section{METHOD}

This study attempted to explore the students' attributions on their English-speaking enhancement. Specifically, the researcher defined the students' speaking enhancement into three specific indicators. They are the students' ability [1] in doing a monologue using English actively in front of the classroom; [2] in asking their friends questions using English actively; and [3] in answering the questions proposed by their friends using English actively. Those indicators were selected since the students frequently performed the activities during the classroom. To achieve the goal, this study used two research instruments, namely openended questionnaire and interview, admitted to be the most frequently used techniques to measure attributions in a number of attribution studies (Farid \& Iqbal, 2012).

\section{Participants}

The study involved eighteen third-semesterstudents who joined English Speaking Community (ESC) program at Sekolah Tinggi Pariwisata Ambarukmo Yogyakarta (STIPRAM), a Tourism Educational Institution in Yogyakarta. The speaking community is one of the compulsory extracurricular programs aiming to enhance the students' English speaking skill. More specifically, the students belonged to Platinum Class, one of the classes in the program. The researcher informed that the students in the class were those who have joined the program held in the previous semester. Besides, they have already obtained a certificate from their previous class stating that their English proficiency belongs to intermediate up to advanced level.

\section{Materials}

Initially, the researcher constructed an openended questionnaire that allowed the participants to provide a detailed and an unlimited number of possible responses (Neuman, 2006). It consists of three statements that were adapted from Tse (2000); Williams, et al. (2004); Yilmaz (2012). Those three statements written in the questionnaire are:

[1] (Until the present time) When I am able to do a monologue using English actively in front of the class, the main reasons are... 
[2] (Until the present time) When I am able to ask my friends questions using English actively, the main reasons are...

[3] (Until the present time) When I am able to answer questions proposed by my friends using English actively, the main reasons are...

Furthermore, in the questionnaire, the researcher translated the statements into Bahasa Indonesia and allowed the participants to provide written responses to the statements using the same language. Its underlying reason was the researcher aimed to ensure that the participants could completely understand the meaning of each statement and eventually could provide clear and deep responses for each statement.

In addition to the questionnaire, the researcher conducted a semi-structured interview, in which the interviewer may ask a series of structured questions to the interviewee and subsequently explore more deeply with open-form questions in order to obtain further information from the interviewee (Gall, Gall, \& Borg, 2007). The interview specifically aimed to ask them to provide further clarification concerning their written responses on the questionnaire, so that the researcher could obtain richer responses from the participants.

The interviewees were three participants who gave various and rich written responses on the questionnaire. Importantly, the willingness to take a part further in this research became another consideration on the selection of the interviewees. Due to the similar reasons, the researcher conducted the interview in Bahasa Indonesia and allowed the interviewees to respond questions in the interview using the same language. To keep the confidentiality of the participants, the names of interviewees were kept in pseudonyms.

\section{Procedures}

The questionnaire was administered to the participants in the class time (on April $26^{\text {th }}$ 2013 and on May $3^{\text {rd }}$ 2013). Before asking them to provide their written responses, the researcher initially explained the participants about the purpose of the study and the meaning of each statement written on the questionnaire. This aimed to ensure that the participants clearly understood the meaning of the statement to which they responded.

The researcher, afterwards, analyzed the written responses on the questionnaire using the grounded theory approach (Strauss and Corbin, 1990, as stated in Neuman, 2006). Briefly, the approach aims to build a theory that faithfully reflects the evidence or, in other words, to build a theory constructed from and grounded in the data. In addition, concerning the approach and related ideas by William, et al. (2004), this study attempted to interpret the meanings that the participants intended and to allow categories to emerge from the data. Accordingly, in this study, the researcher interpreted the written responses on the questionnaire by underlining the responses that could possibly become the attributions on the students' Englishspeaking enhancement. These possible attributions were subsequently put in some tables in order to help the researcher easily classify the attributions based on each indicator.

The interview section was conducted after administering the questionnaire (on $7^{\text {th }}$ and $8^{\text {th }}$ May 2013). During the interview process that was recorded using a voice recorder, both every selected participant and together with the researcher saw his/her written responses on the questionnaire. In that case, the researcher led the participants to provide further clarification towards what they had written on the questionnaire. The recorded oral information of the interview was then transcribed and analyzed by the 
researcher in order to support the data obtained from the questionnaire.

\section{FINDINGS AND DISCUSSION}

The research aimed to answer the question; What are students' attributions for the enhancement of their English speaking ability in English Speaking Community (ESC) class? In answering the research question, the researcher defined the participants' English speaking enhancement into three specific indicators. They are the students' ability in doing a monologue using English actively in front of the classroom; in asking their friends questions using English actively; and in answering the questions proposed by their friends using English actively. Therefore, in this part, the researcher aimed to display the research results of the attributions based on each indicator.

Specifically, the researcher would discuss the research results obtained from the questionnaire data that would show some attributions categories that the students had for each indicator. Importantly, the name of the attributions' categories shown in some Tables in this part were adapted and developed from Williams, et al. (2004); Yilmaz (2012). Then, the data obtained from the interview would also support the research results from the questionnaire. Eventually, the results would become the answer to the research question stated in this study.

\section{The Students' Attributions for Their Ability in Doing a Monologue Using English Actively}

Initially, the researcher needs to clarify the term English monologue used in this study. It refers to an activity in which the teacher of the program asks his students to come in front of the classroom and subsequently to share a particular story that can be about their family, holiday experience, and special person in their life, using English language.

As the results of the analysis, the researcher found seven attributions that the participants had for their ability in doing the monologue using English actively. Table 1 elaborated the attributions into a ranked order.

Table1. The students' attributions for their ability to do a monologue using English actively

\begin{tabular}{|c|c|c|}
\hline Attributions & Number & Percentage \\
\hline Strategy & 10 & $26.3 \%$ \\
\hline Need/Importance & 9 & $23.7 \%$ \\
\hline Positive motivation/encouragement from friends & 8 & $21 \%$ \\
\hline Positive motivation/encouragement from the teacher & 6 & $15.8 \%$ \\
\hline Self-confidence & 2 & $5.3 \%$ \\
\hline Rewards from teacher & 2 & $5.3 \%$ \\
\hline Positive classroom environment & 1 & $2.6 \%$ \\
\hline Total Number & 38 & $100 \%$ \\
\hline
\end{tabular}

As displayed in Table 1, strategy (26.3\%) became the major category frequently mentioned by the participants. As adapted from Williams, et al (2004) who state that to differentiate between effort and strategy is not easy to do, this study, therefore, regarded the term strategy operationally as a directed effort.

This category included statements such as "I practice speaking in English at home, in front of my friends, and in front of the mirror." Other statements included in this category were "I keep reviewing the 
materials that I get from the classroom, listen to my teacher's explanation during the class, actively use English in my working places, and often communicate with foreigners." Further, the category covered some other statements, such as "I joined English competitions when I was in Senior High School, look at a dictionary, watch English movies, and I started to communicate in English during my English lesson in classroom when I was in my vocational school."

Some statements proposed by the participants corresponded to what some of the participants conveyed in the interview. Dealing with listening to teacher's explanation during the class, a participant conveyed that:

Some students usually talk each other and tend not to listen to the teacher's explanation. Unlike them, I prefer to listen to my teacher when he explains something in the classroom. It helps me understand the monologue.

(Luna-interview-A.1.8-STR-

translated by the researcher)

On the questionnaire, another participant also mentioned a statement that was related to practice speaking English in front of friends. In the interview, the participant further clarified that the practice was in the form of discussions with friends. The discussions were likely to provide an opportunity for the interviewee to speak in English and to affect her being able to do the monologue in the classroom:

Additionally, my friends and I sometimes have a discussion in which we try to use English, so I am accustomed to speak in English. Consequently, I dare to come in front of the classroom and subsequently to do the monologue.

(Ana-interview-A.2.7-STR- translated by the researcher)
Another prominent attribution stated by the participants was termed need/importance $(23.7 \%)$. This category involved such statements as "I have a self-awareness to enhance my English skill, functioning as a valuable asset for my future; I need to obtain some feedback from my friends and to enhance my self-confidence." Besides, "I consider the monologue as a right way to enhance my English speaking skill; by doing the monologue, I intend to motivate my friends, express my feeling, and to be able to communicate closely to my friends."

Positive motivation/ encouragement from friends $(21 \%)$ became the next attribution that was mentioned frequently by the participants. This might indicate that friends became an essential factor affecting the students' success in doing their English monologue. This attribution category included such statements as "my friends' English skill can motivate me to keep studying English, more specifically the English monologue; my friends motivate and encourage me to do the monologue in front of the classroom." These statements were in line with those clarified in the interview, as what some interviewees said:

At that time, Mr... asked me to perform the monologue in front of the class. Then, my friends encouraged and motivated me to do it. As a result, I dare and am confident to do the monologue.

(Ana-interview-A.2.6-FRN-translated by the researcher)

It is due to my friends; my friends in my groups are active and able to do the monologue well. Besides, they encourage me to try to perform the monologue more bravely.

(Ela-interview-A.3.5-FRN- translated by the researcher)

Similarly, the next attribution to emerge was related to positive motivation/ encouragement. However, unlike the 
previous attribution, this attribution category dealt with the teacher. It was termed positive motivation/ encouragement from the teacher $(15.8 \%)$. It included such statements as "my teacher motivates and encourages me to dare in doing the monologue in front of the class, to speak English fluently; my teacher frequently asks us to speak in front of the classroom, and I have a nice and friendly teacher who helps me develop my skill and minimize my anxiety in the classroom." Those four previous attributions became the categories that were frequently mentioned by the participants for their being able in doing the monologue using English actively.

The Students' Attributions for Their Ability in Asking Questions Using English Actively

Based on the analysis results of the questionnaire, the researcher found eight attributions that the participants had for their ability to ask their friends questions using English actively. The results were completely displayed in Table 2.
In that case, need/importance $(32.1 \%)$ became the major reason for their being able to ask questions using English actively. The comments in this category included: "by doing so, I want to enhance my knowledge, be able to make myself speak English fluently, assess my skill in asking my friends English questions, enhance my selfconfident, practice using English language." This category covered further statements, such as "I want to encourage my friends to speak English more actively; know my friends' respond concerning a particular problem."

Strategy $(28.6 \%)$ was another frequently attribution emerged on the questionnaire. Concerning this category, some participants stated that "I listen carefully to the material that my friends presented, make the questions in Indonesian language, and subsequently translate them into English language; I frequently chat with foreigners using English in skype, and practice asking questions at home." In the interview, a participant clearly articulated similar point of views to this attribution category:

Table 2. The Students' Attributions for Their Ability to Ask Questions Using English Actively

\begin{tabular}{lcc}
\hline \multicolumn{1}{c}{ Attributions } & Number & Percentage \\
Need/ Importance & 9 & $32.1 \%$ \\
Strategy & 8 & $28.6 \%$ \\
Positive motivation/encouragement from the teacher & 3 & $10.7 \%$ \\
Self-confidence & 3 & $10.7 \%$ \\
Positive motivation/ encouragement from friends & 2 & $7.1 \%$ \\
Rewards from teacher & 1 & $3.6 \%$ \\
Interesting presentation by another student & 1 & $3.6 \%$ \\
Having background knowledge to what his/ her friends said/ presented & 1 & $3.6 \%$ \\
\multicolumn{1}{c}{ Total Number } & 28 & $100 \%$ \\
\hline
\end{tabular}

As an example, if there are English vocabularies that I do not understand yet, I try to find out their meaning by looking at a dictionary or by asking other people. As a result, I can have more vocabularies and subsequently use them in my daily life. Chatting becomes another reason; I, for 
instance, frequently use English to make some jokes with my friends.

(Luna-interview-A.1.12-STR-translated by the researcher)

Sometimes, if I find it difficult to ask a particular question because I do not exactly know how to say it in English, I start to make the question in Bahasa Indonesia. Subsequently, I translate it into English. It helps me a lot.

(Ela-interview-A.3.10-STR-translated by the researcher

Positive motivation/encouragement from the teacher $(10.7 \%)$ became the next attribution to emerge in the data, which included such comments as "Mr..., the teacher of the program, keeps encouraging me to ask the questions without being afraid to make mistakes; my teacher is very active." Moreover, "my teacher gives tasks which enable the students to ask questions one another; that my teacher is able to speak English fluently really affects me to be able to ask the questions."

The data also showed that selfconfidence $(10.7 \%)$ became the next attribution that the participants had for their ability in asking questions using English actively. This category included statement such as "the fact that I have a good selfconfident affects my being able to ask questions using English fluently." Consistent with the questionnaire results, a participant conveyed the following ideas:

I am sure with my ability to propose the question and the mastery of the material that I have. Therefore, I confidently propose ask the questions to my friends. (Anainterview-A.2.12-SFD- translated by the researcher)

Furthermore, Table 2 showed other less frequent attributions categories. They were positive motivation/encouragement from friends $(7.1 \%)$ and rewards from teacher (3.6\%) for the students' ability in asking their friends questions using English actively.

\section{The Students' Attributions for Their Ability in Answering Questions Using English Actively}

Concerning the last indicator, which is the students' ability to answer questions using English actively, the researcher, as displayed in Table 3, found ten (10) different attributions emerged from the questionnaire data. Similar to the previous indicators, the major categories frequently mentioned by the participants were need/importance (19.2\%), strategy $(19.2 \%)$, and self-confidence $(15.5 \%)$.

Table 3. The students' attributions for their ability to answer questions using English actively

\section{Attributions}

Need/ Importance

Strategy

Self-confidence

Build positive environments

Positive motivation/encouragement from the teacher

Having background knowledge to what his/ her friends said/ presented

Vocabulary mastery

Clarity of the questions

Rewards from teacher

Positive motivation/ encouragement from friends
Number Percentage

$19,2 \%$

$19,2 \%$

$15.5 \%$

$7,7 \%$

$7.7 \%$

$7.7 \%$

$7.7 \%$

$7.7 \%$

$3.8 \%$

$3.8 \%$

Total Number

26


The category of need/ importance included such statements as "I view that answering questions is one of the things that I can do to enhance my English speaking skill. Additionally, by doing so, I can enhance my self-confidence and English skill." Then, the category of strategy involved these statements, such as "I frequently practice speaking in English at home, practice answering English questions, have a frequent chatting with people from other countries." Such statements as "I have a confident to answer the questions; the confident that I build in ESC class helps me to answer the questions were what the participants mentioned for the selfconfidence category."

Besides those three prominent attributions cited by the participants, the researcher found some other attribution categories that were less frequently cited by the participants. The first category was termed positive motivation/ encouragement from the teacher $(7.7 \%)$. Then, having background knowledge to what his/her friends said/presented $(7.7 \%)$ became the second category cited by the participants, as what has been clarified by an interviewee:

I really understand the contexts that were being discussed at that time. Based on that reason, I can answer my friends' questions. (Luna-interview-A.1.14-BGK-translated by the researcher)

The third category was termed vocabulary mastery $(7.7 \%)$. This category involved a statement such as "I have mastered many vocabularies, which helps me understand what is being asked." This statement emerged from the questionnaire data was in harmony to what a participant stated in the interview:

As what I have explained in the second question, having a number of vocabularies means that, we can understand the questions stated by our friends.
(Luna-interview-A.1.14-VOC- translated by the researcher)

Then, the fourth category was termed clarity of the questions (7.7\%). Culturally interesting, build positive environments $(7.7 \%)$ became the next infrequently attribution categories cited by the participants. This category included such comments, as "by answering the questions, I want to provide a satisfaction for my friends who ask the questions and to appreciate my friends who are willing to ask me the questions." Last, rewards from teacher (3.8\%) and positive motivation/ encouragement from friends $(3.8 \%)$ were considered the last category that was cited infrequently by the participants.

In this study, the researcher defined the students' speaking enhancement into three specific indicators. The results of the analysis showed that need/importance and strategy stood out as the most widely cited attributions for each indicator. In relation to the need/importance attribution category, most of the participants mentioned that they were able to do the monologue, ask their friends, and answer the questions using English actively since they considered doing them as a good practice to enhance their English speaking skill and self-confidence. In other words, the results may be a demonstration that they could use English actively because they needed to practice and subsequently to enhance their selfconfidence and English speaking skill.

From these findings, the researcher might also observe that most of the participants, considered as the non-English Department students, had already understood either the essence or the purpose of doing the monologue, asking, and answering questions using English actively. Therefore, the findings of the research would seem to demonstrate that understanding the essence or the purpose of doing those three activities 
possibly affects the participants' ability to do the activities well.

Further, the findings dealing with need/importance attribution might propose a considerable possibility that teachers indeed had a vital role in the classroom, more specifically in the non-English Deparment classroom setting. In that case, teachers essentially needed to explain the essence as well as the purpose of doing particular English speaking activities. This might enable the teachers to help their students understand why they should do the speaking activities in their classroom. Once the students indeed understood the essence of doing a particular English speaking activity, teachers might expect them to be able to do the activity well.

Then, strategy turned out to be another most frequently cited attribution in this study and at the same time supported the findings of Williams, et al. (2004) study. Clearly, this category showed the various activities that the participants did in order to be able to do a monologue, to ask and to answer questions using English actively. Some of the activities were to keep reviewing the materials obtained from the classroom, to practice speaking in English in front of the mirror, to make the questions in Indonesian language and then translate them into English language, and to have a frequent chat with foreigners through skype.

Considering the strategy, as another prominent attribution mostly cited by the participants, the research would seem to indicate that most of the participants had already learnt and practiced the types of the English speaking strategies. Therefore, teachers could help their students to develop more various speaking strategies. More specifically, teachers could humbly share their experiences on what to do and what to prepare, so they could do the activities stated in each indicator well. Obtaining the inputs, students could be expected to enhance their
English speaking skills, more specifically in doing the monologue in front of the classroom, in asking, and in answering questions using English actively.

Furthermore, the results of the study showed that positive motivation/ encouragement from friends as well as from the teacher became the next common attributions that the participants had for their English-speaking enhancement. These two attributions, along with the comments stated by the participants, might give a rise to the importance of promoting the positive relationships between students and a teacher as well as among the students themselves in the classroom. Those ideas on positive relationships are in harmony with the findings of some previous related studies regarding teachers' support and community interactions as the attributions for the success in the students' language learning (Tse, 2000); and teachers' influence as attributions for the students' positive classroom performance (Lei \& Qin, 2009) as cited in Pishghadam and Zabihi, (2011); Thang, et al. (2011).

\section{CONLUSION}

To sum up, a clear purpose of doing particular English speaking activities, the strategy, and the positive relationships between the students and the teacher as well as among the students themselves were revealed as the primary students' attributions on their English-speaking enhancement. Importantly, the findings of the current study could serve as a starting point to suggest some pedagogical implications. Firstly, the role of the teacher in the classroom should not merely focus on transferring knowledge to their students (Harmer, 2007) but should also maintain the positive relationships with their students and among the students themselves. Secondly, students need to be encouraged to keep developing a proper learning strategy for their English speaking. 
In that case, it is also possible for teachers to share their experience on ways to be able to do an English monologue, to ask, and to answer questions using English actively. Besides, inviting students to share their experience on learning strategies that they usually do in practicing English speaking effectively becomes another possibility to do within the classroom. Thirdly, students need to understand essence and purposes of doing particular English speaking activities in their classroom. In that case, teachers should clearly explain why their students have to perform a particular speaking activity in their classroom. Finally, it is expected that this study could contribute to the development the teaching and learning process in English speaking classrooms specifically in Indonesian context.

\section{REFERENCES}

Asonibare, B. (1986). Attribution of failures and success by Nigerian secondary school students. Ilorin Journal of Education, 6, pp.15-22.

Banks, M., \& Woolfson, L. (2008). Why do students think they fail? The relationship between attributions and academic selfperceptions. British Journal of Special Education, 35(1), pp.49-56.

Ellis, R. (2008). The study of second language acquisition ( $2^{\text {nd }}$ ed.). Oxford: Oxford University Press.

Farid, M.F., \& Iqbal, H.M. (2012). Causal attribution beliefs among school students in Pakistan. Interdisciplinary Journal of Contemporary Research in Business, 4(2), pp.411-424.

Gall, M.D., Gall, J.P., Borg, W.R. (2007). Educational research: An introduction ( $8^{\text {th }}$ ed.). Boston: Pearson Education, Inc.

Gobel, P., \& Mori, S. (2007). Success and failure in the EFL classroom: Exploring students' attributional beliefs in language learning. In L. Roberts, A.
Gürel, S. Tatar, \& L. Martı (Eds.), EUROSLA Yearbook 7 (pp. 149-169).

Amsterdam: John Benjamins Publishing Company.

Gonzales, A.S. (2011). Attribution theory and culture: using focus groups to uncover parameters of influence. Language studies working papers, 3, pp.29-37.

Harmer, J. (2007). The practice of English language teaching. Essex: Pearson Education Limited.

Lei, C. (2009). On the causal attribution of academic achievement in college Students. Asian Social Science, 5(8), pp.87-96.

Luoma, S. (2004). Assessing speaking. Cambridge: Cambridge University Press.

Mori, S., Gobel, P., Thepsiri, K., \& Pojanapunya, P. (2010). Attributions for performance: A comparative study of Japanese and Thai university students. JALT Journal, 32(1), pp.5-28.

Neuman, W.L. (2006). Social research methods qualitative and quantitative approaches $\left(6^{\text {th }}\right.$ ed.). Boston: Pearson.

Pishghadam, R., \& Zabihi, R. (2011). Foreign language attributions and achievement in foreign language classes. International Journal of Linguistics, 3(1), pp.1-11.

Thang, S.W., Gobel, P., Mohd. Nor, N.F., \& Suppiah, V.L. (2011). Students' attributions for success and failure in the learning of English as a second language: A comparison of undergraduates from six public universities in Malaysia. Pertanika J. Soc. Sci. \& Hum, 19(2), pp.459-474.

Tse, L. (2000). Student perceptions of foreign language study: a qualitative analysis of foreign language. The Modern Language Journal, (84)1, pp.69-84. 
Indonesian Journal of Applied Linguistics, Vol.4 No.2, January 2015, pp. 32-43

Ur, P. (1996). A course in language teaching. Cambridge: Cambridge University Press.

Weiner, B. (1972). Attributions theory, achievement motivation, and the educational process. American Educational Research Association, 42(2), pp.203-215.

Williams, M., Burden, R.L., Poulet, G.M.A., \& Maun, I.C. (2004). Learners' perceptions of their successes and failures in foreign language learning. Language Learning Journal,30, pp.1929.

Yilmaz, C. (2012). An investigation into Turkish EFL students' attributions in reading comprehension. Journal of Language Teaching and Research, 3(5), pp.823-828. 